\title{
Echocardiographic evaluation of simple versus complex congenital heart disease in a tertiary care Paediatrics Hospital
}

\author{
Uttam Kumar Sarkar ${ }^{1}$, Anish Chatterjee ${ }^{2}$, Suprit Basu ${ }^{2}$, Atanu Pan $^{3}$, Sumit Periwal ${ }^{1}$ \\ ${ }^{1}$ Dr.B.C.Roy P.G.I.P.S. Kolkata, ${ }^{2}$ Resident Medical officer, I.P.G.M.E.\&R. Kolkata, ${ }^{3}$ Department of \\ Pediatric Medicine,College of Medical Sciences, Bharatpur, Nepal
}

\section{Correspondence}

Dr. Suprit Basu

Resident Medical officer,

I.P.G.M.E.\&R. Kolkata

\section{Email:}

supritbasu94@gmail.com

DOI: http://dx.doi.org/10.3126/ jemsn.v13i3.18404

Orcid ID: orcid.org/0000-00032016-3272

Article received: June $27^{\text {th }} 2017$ Article accepted: Sept $1^{\text {st }} 2017$

\begin{abstract}
Background \& Objectives: Congenital heart diseases are treatable either by catheter based intervention or open heart surgery according to their quality. In our study we aim to analyze congenital heart disease echocardiographically into simple versus complex heart disease at a tertiary care centre with a public health planning and policy making perspective. Materials \& Methods: This hospital based study was done on 1010 patients, both from in-patient and out-patient, who were clinically suspected to have heart disease from January 2015 to September 2016 at Dr.B.C.Roy P.G.I.P.S. Kolkata and echocardiographically categorized. Results: A VSD was the commonest acyanotic heart disease (17. 08\%).Tetralogy of Fallot (TOF) was commonest complex cyanotic heart disease (10.64\%), VSD +ASD was the commonest combined lesion $(8.12 \%)$. Simple heart lesions $(63.1 \%)$ were commoner than complex $(36.9 \%)$ congenital heart diseases. Conclusion: Health policy makers should give due care to manage Congenital Heart Disease either catheter based or surgically keeping in mind about $63.1 \%$ of the lesions are simple cardiac lesions and $36.9 \%$ lesions are complex cardiac lesion where complex surgery is required.
\end{abstract}

Key words: Catheter based intervention; complex congenital heart disease; congenital heart disease (CHD); simple congenital heart disease

Citation: Sarkar UK, Chatterjee A, Basu S, Pan A, Periwal S. Prevalence Echocardiographic evaluation of simple versus complex congenital heart disease in a tertiary care Paediatrics Hospital. JCMS Nepal. 2017;13 (3):327-9.

\section{INTRODUCTION}

The burden of congenital heart defects are considerable problem which are yet to be solved. ${ }^{1}$ In India this burden is likely to be enormous with high mortality and morbidity due to a high birth rate. Congenital heart diseases are leading cause of mortality in first year of life. ${ }^{2,3,4}$ Saxena $A^{5}$ reported $10 \%$ mortality in infancy is due to CHD in India. The prevalence of CHD varies in different studies in India. The incidence of CHD is 3.9/1000 live births as recorded in large hospital based study by Khalil et al6 from India, whereas prevalence of CHD in community based studies range from 0.8 to $5.2 / 1000$ patients. $^{7,8}$ Of these heart diseases some are simple , some complex. ${ }^{1,2}$ Simple lesions are defined as a hole in the septum, narrow valve and vessels. ${ }^{9}$ Complex defects are a combination of these simple defects, problems with location of blood vessels leading to and from the heart and more serious problems associated with how the heart develops. Complex heart disease needs surgery. Some lesions are very small without any hemodynamic significance, only observation and follow-up is required. Patent Foramen Ovale was thought to be inconsequential until 1987, when Cohnheim postulated that a venous thrombus may paradoxically traverse foramen ovale and give rise to systemic embolism. ${ }^{9,10}$ For proper management, categorisation into simple or complex heart disease is needed. Simple defects are usually managed by catheter based device closure but some require surgery. Secundum ASD is currently amenable to 
surgery. Multiple ASD can be treated with single or multiple devices as and when necessary. Closure of large ASD may be done either by device or surgery, which has been shown to increase exercise tolerance. $^{12}$ VSD accounts for about $20 \%$ of all forms of CHD. Muscular VSD most amenable to device closure. Transcatheter PDA occlusion is indicated for the treatment of a moderate to large sized PDA with left to right shunt that results in any of the following-congestive heart failure, failure to thrive, pulmonary over circulation or an enlarged left atrium or left ventricle, provided the anatomy and ductus size are suitable. Our aim of this study is to determine the incidence of congenital cardiac lesions and categorization of them into simple and complex types.

\section{MATERIALS AND METHODS}

This study was conducted at Dr. B.C. Roy P.G.I.P.S. Kolkata, India from January 2015 to September 2016. This is a retrospective descriptive study. Total number of patients evaluated echocardiographically (transthoracic -2D, M mode, colour Doppler) is 1010 aged up to 12 years from pediatric outpatient and in-patient department. Only clinically suspected cardiac diseases were evaluated echocardiographically and those with defects were classified into simple and complex heart disease. Acquired heart disease like rheumatic heart disease, Kawasaki diseases were excluded from the study.

\section{RESULTS}

Out of 1010 patients studied, 357(35.34\%) had congenital cardiac lesions. Among these 357 patients, $231(64.7 \%)$ were male and $126(35.3 \%)$ were female. Most of them were detected in infancy $274(76.75 \%)$ and some were diagnosed late beyond five years $28(7.85 \%)$. Some defects were simple $224(63.1 \%)$ some were complex 133 $(36.9 \%)$.Among the significant lesions, VSD was the most common 61(17.0\%) followed by ASD 43 $(12.0 \%)$ and PDA 42(11.8\%).We had isolated PS in five patients, coarctation of aorta in two and bicuspid aortic valve in two patients. Amongst the complex lesions, TOF $38(10.6 \%)$ was the commonest followed by DORV 13(3.6\%) and TGA seven $(1.9 \%)$, AVSD six, TAPVC three, Truncus arteriosus two and Tricuspid atresia in two patients. Some of the cardiac lesions were multiple in a single patient which might be device closurable or require surgery to be determined by further study like VSD plus ASD 29(8.1\%), VSD plus PDA 13 (3.6\%), VSD plus ASD plus PDA 11(3.0\%). Some of the lesions require minimal follow up only like PFO 69(19.3\%).

\section{DISCUSSION}

In our study $64.7 \%$ were male with male/female ratio 1.8:1. In the study of Baspinor $\mathrm{Q}$ et al, ${ }^{18}$ male/ female was $1: 1$. Shah GS et $\mathrm{al}^{19}$ found male to female ratio1.5:1. In our study most of the CHD were detected in infancy $(76.7 \%)$ and $7.8 \%$ of beyond five years. Saleh $\mathrm{HK}^{20}$ observed CHD in $39.8 \%$ in infancy. Kiran $\mathrm{B}$ et $\mathrm{al}^{21}$ also detected CHD $35.7 \%$ in infancy. In our study VSD was the commonest acyanotic heart disease (17.0\%) followed by ASD \& PDA. Our findings are as per Hajela $S$ et al. ${ }^{22}$ In our study, Tetralogy of Fallot was commonest cyanotic heart disease $(10.6 \%)$ followed by DORV, TGA, AVSD, TAPVC. This findings are similar to Hajela Set $a^{22} .^{22}$ About the combined lesion we found VSD+ASD in $8.1 \%$ patients which tallies with Kiran B et al. ${ }^{21} \mathrm{We}$ found PFO in $19.3 \%$ cases , whereas it is $12 \%$ in Kiran B et al. ${ }^{21} \mathrm{We}$ found simple congenital cardiac lesion in $63.1 \%$ and complex in $36.9 \%$.This finding is similar to Hajela $\mathrm{S}$ et $\mathrm{al}^{22}$ where simple and potentially correctable heart defects like VSD $29 \%$, ASD $13 \%$, PDA $5 \%$, which cumulates to $47 \%$.

\section{CONCLUSION}

In the era of technical advancement, cardiac intervention has reduced the cost, morbidity and mortality by making congenital cardiac lesions accessible in minimally invasive fashion. Majority of congenital heart disease are simple heart defects and can be managed by minimally invasive technique with a good outcome. Though some of the single lesions may be the domain of CTVS

Table 1: Age-wise and disease-wise distribution

\begin{tabular}{llll} 
Age (years) & Simple heart defect & Complex heart defect & Total, $\mathrm{n}(\%)$ \\
$0-1$ & 160 & 114 & $274(76.7 \%)$ \\
$1-5$ & 45 & 10 & $55(15.4 \%)$ \\
$5-12$ & 19 & 9 & $28(7.9 \%)$ \\
Total n (\%) & $224(63.1 \%)$ & $133(36.9 \%)$ & $357(100 \%)$ \\
\hline
\end{tabular}


Table 2: Specific disease-wise distribution of simple and complex heart defects

$\begin{array}{lll}\text { Simple heart defect } & \text { No. } & \text { Percent } \\ \text { VSD } & 61 & 17 \\ \text { ASD } & 43 & 12 \\ \text { PDA } & 42 & 11.8 \\ \text { Isolated PS } & 5 & 2.2 \\ \text { PFO } & 69 & 19.3\end{array}$

\section{Complex heart defect}

\begin{tabular}{lll} 
TOF & 38 & 10.6 \\
\hline DORV & 13 & 3.6 \\
TGA & 7 & 2.0 \\
\hline AVSD & 6 & 1.8 \\
TAPVC & 3 & 0.9 \\
Truncus arteriosus & 2 & 0.6 \\
Tricuspid atresia & 2 & 0.6 \\
VSD+ASD & 29 & 8.1 \\
VSD+PDA & 13 & 3.6 \\
VSD+ASD+PDA & 11 & 3.0
\end{tabular}

surgeon due the size, position or pressure dynamics yet minimally invasive catheter based interventions form an integral part of treatment of these CHD also. Our attempt is to delineate the problem primarily from the policy-maker's point of view specially in developing countries but more multicentric trials are required to find more data as a guide to national health policy.

\section{REFERENCES}

1. Mitchell SC, Koranes SB, Berendes HW. Congenital Heart Disease in 56109 births. Incidence Natural History. Circulation 1971; 43:323-32. https:// doi.org/10.1161/01.CIR.43.3.323. PMID: 5102136.

2. Fyler DC,Buckley LP,Hellenbrand WE,Cohn HE .Report of the New England regional infant care program. Pediatrics. 1980;65:375-461.

3. Abdulla R.What is the prevalence of congenital heart disease .Pediatric Cardiology.1997 Jul-Aug;18(4):269. https://doi.org/10.1007/s002469900172. PMID: 9175522.

4. 4. Hoffmann JIE, Samuel Kaplan. Incidence of congenital heart disease (Review article) J Am Coll Cardiology. 2002;39:1890-1900. https://doi.org/10.1016/S0735-1097 (02)01886-7.

5. Saxena A. Congenital heart disease in India: A status report. Indian J Pediatrics. 2005;72:595-8. https:// doi.org/10.1007/BF02724185.

6. Khalil A, Aggarwal R, Thirupuram S, Arora R. Incidence of congenital heart disease among hospital live births in India. Indian Pediatr. 1994:31:519-24. PMID: 7875882.

7. Gupta J, Gupta ML, Parihar A, Gupta CD. Epidemiology of Congenital \& Rheumatic Heart Disease in School Children. J Ind Med Association. 1992;90:57-9. PMID: 1634785.

8. Vashishta VM, Kalra A, Kalra K, Jain VK. Prevalence of congenital heart disease. Indian Pediatr. 1993;30:1337-40.

9. Types of Congenital Heart Defects. National Heart, Lung and Blood institute. Types of Congenital Heart Defects [Internet] Accessed: 21st July 2017. Available from: https://www.nhlbi.nih.gov/health/health-topics/topics/chd/ types.
10. Formigasi R, DiDonatoRM, Mazzra E. Minimally invasive or interventional repair of atrial septal defect in children experience in 171 cases and comparison with conventional strategies. J Am Coll Cardiol. 2001;37(6):1707-12. https:// doi.org/10.1016/S0735-1097(01)01213-X.

11. Cowley CG, Lloyd TR, Bove EL, Gaffney D, Dietrich M , Rocchini AP Comparison of results of closure of secundum atrial septal defect by surgery versus Amplatzer Septal occlude.Am J Cardiol. 2011;88:589-91. https:// doi.org/10.1016/S0002-9149(01)01750-7

12. PodnarT, Mastonoric $P$, Gavora P. Morphological variation of secundum type Atrial septal defects:Feasibility for percutaneous closure using Amplatzer septal occluders.Catheter Cardiovasc. Intervention 2001;53:386391. https://doi.org/10.1002/ccd.1187. PMID:11458420.

13. Brochu MC, Baril JF, Dore A. Improvement in exercise capacity in asymptomatic and mildly symptomatic adults after atrial septal defect percutaneous closure. Circulation. 2002;106:1821-26.

doi.org/10.1161/01.CIR.0000029924.90823.E0. PMID:12356636.

14. Arora R, Trehan V, Thakur AK, Mehta V, Sengupta PP, Nigam M. Transcatheter closure of congenital muscular ventricular septal defect. J Intervention Cardiol. 2004;17:109-115. https://doi.org/10.1111/j.15408183.2004.09872.x. PMID: 15104774.

15. Beckman RH, Rocchino AP, Dick M. Percutaneous Balloon Angioplasty for native coarctation of aorta. J AM Coll Cardiol. 1987;10:1078. https://doi.org/10.1016/S07351097(87)80349-2.

16. Singer MI, Rowen M, Dorsey TJ. Transluminal aortic balloon angioplasty for coarctation of aorta in the newborn. Am Heart J. 1982;103:131. https://doi.org/10.1016/00028703(82)90539-7.

17. Cohnheim J. Thrombosis and embolic:Vorlesurg uber allgemain Pathologic Berlin;134:1877

18. Baspinar O, KaraslanS, OranB, Baysal T, Elmaci AM, Yousulmaz A. Prevalence and distribution of children with congenital heart diseases in the Central Anatolian region, Turkey. Turk J Pediatr. 2006 July-Sep;48(3):237-43. PMID: 17172068.

19. Shah GS, Singh MK, Pandey TR, Kalakheti BK, Bhandari GP. Incidence of congenital heart disease in tertiary care hospital. Kathmandu Univ Med J. 2008 Jan-Mar;6(1):336.

20. Saleh HK. Pattern of congenital heart disease in Southern Yemini children referred for echocardiography. Saudi Med J. 2009 Jan;30(6):824-8. PMID: 19526169.

21. Kiran B, Chintan S, Chandramohan Reddy, Savitha S, Supriya S Medhar, Keerthana TN. Study of prevalence of congenital heart diseases in children in a rural tertiary care hospital. International Journal of Pediatric Research. Dec 2016;3(12):887-9.

22. Hajela S. Profile of Congenital Heart Disease in childhood. International Journal Of Medical Research \& Review. May -June 2014;2(3):234-6. 